\title{
Pengembangan Modul Pembelajaran Berbasis Inkuiri Terbimbing pada Mata Pelajaran Dasar Listrik dan Elektronika Kelas X di Sekolah Menengah Kejuruan
}

\author{
Andri Domara $^{1 *}$, Asnil ${ }^{1}$ \\ ${ }^{1}$ AJurusan Teknik Elektro, Fakultas Teknik, Universitas Negeri Padang \\ Jln. Prof. Dr. Hamka Air Tawar Padang 25131 INDONESIA \\ *e-mail: andridomara22@gmail.com \\ (Diajukan: 12 September 2020: 3 Oktober 2020, disetujui: 31Oktober 2020)
}

\begin{abstract}
Abstrak
Penelitian ini bertujuan untuk menghasilkan modul pembelajaran yang valid dan praktis pada mata pelajaran Dasar Listrik dan Elektronika kelas X TITL di SMK Negeri 2 Sawahlunto. Penelitian ini menggunakan metode penelitian pengembangan (Research and Development) dengan model 4D. Subjek penelitian ini adalah siswa kelas X TITL 1 di SMK Negeri 2 Sawahlunto pada semester satu tahun ajaran 2020/2021. Berdasarkan hasil penelitian diperoleh validitas instrumen peneltian rata-rata $92 \%$ dengan kategori valid. Uji validitas media 90\% dengan kategori valid. Validitas materi rata-rata sebesar $89 \%$ dengan kategori valid. Uji praktikalitas dengan responden guru rata-rata sebesar 86,5\% dengan kategori sangat praktis dan responden siswa kelas X TITL 1 SMK Negeri 2 Sawahlunto dengan nilai rata-rata $85 \%$ menyatakan modul pembelajaran berbasis inkuiri terbimbing Dasar Listrik dan Elektronika dikategori sangat praktis. Disimpulkan bahwa modul pembelajaran berbasis inkuiri terbimbing Dasar Listrik dan Elektronika sudah valid dan praktis sehinggadapat digunakan dalam proses belajar mengajar di sekolah.
\end{abstract}

Kata Kunci: Inkuiri, valid, praktis, dasar listrik dan elektronika, Research \& Development (R\&D).

\begin{abstract}
This research aims to produce a valid and practical learning module on basic Electrical and Electronic subjects grade X TITL at SMK Negeri 2 Sawahlunto. This research uses research and development methods with 4D models. The subject of this study was grade $X$ TITL 1 students at SMK Negeri 2 Sawahlunto in the first semester of the 2020/2021 school year. Based on the results of the study obtained the validity of research instruments on average $92 \%$ with valid categories. Test $90 \%$ media validity with valid categories. The average material validity is $89 \%$ with valid categories. Practicality test with average teacher respondents of $86.5 \%$ with very practical category and respondents of grade $X$ TITL 1 SMK Negeri 2 Sawahlunto with an average score of $85 \%$ stated learning module based on the guided inkuiri Basic Electricity and Electronics category is very practical. It concluded that the inkuiri-based learning module guided by Electricity and Electronics is valid and practical so that it can be used in the learning process of teaching in schools
\end{abstract}

Keywords: Inkuiri, valid, practical, electrical and electronic-base learning, Research \& Development $(R \& D)$. 


\section{PENDAHULUAN}

Pendidikan merupakan faktor utama dalam pembentukan karakter dan kepribadian manusia[1]. Pendidikan adalah proses pembelajaran dan mewujudkan suasana belajar agar peserta didik secara aktif untuk mengembangkan keahlian dirinya untuk mempunyai kekuatan kecerdasan, kepribadian, spiritual agama, akhlak mulia, keterampilan yang diperlukan dirinya, masyarakat, bangsa, Negara dan pengendalian diri [2]. Pendidikan bertujuan untuk mengembangkan kemampuan dan potensi peserta didik agar menjadi manusia yang berpengetahuan, kreatif, dan mandiri. Namun, untuk pencapaian tujuan tersebut tidak terlepas dari pembelajaran yang merupakan proses interaksi siswa dengan pendidik dan sumber belajar pada suatu lingkungan belajar berupa sekolah. Salah satu satuan pendidikan tersebut ialah sekolah menengah kejuruan (SMK)

Seorang guru harus mampu menimbulkan semangat belajar individual peserta didik. Karena masing-masing peserta didik mempunyai perbedaan dalam pengalaman, kemampuan dan sifat-sifat pribadi lainnya, sehingga dapat memberikan kebebasan dan kebiasaan bagi peserta didik untuk mengembangkan kemampuan berpikirnya dengan penuh inisiatif dan kreatif dalam pekerjaannya. Hal itu mengharuskan guru untuk membuat perencanaan secara individual pula, agar dapat mengembangkan kemampuankemampuan peserta didik secara individual. Agar peserta didik dapat mengembangkan kemampuannya dalam belajar maka diperlukan bahan ajar yang mendukung proses pembelajaran. Salah satu bentuk bahan ajar adalah modul. Modul pembelajaran merupakan suatu unit bahan yang disusun secara khusus sehingga dipelajari oleh pelajar secara mandiri [3].

Berdasarkan hasil observasi selama bulan Agustus 2019 dengan pengamatan proses pembelajaran siswa kelas $X$ dan pengamatan langsung terhadap guru-guru TITL di SMK Negeri 2 Sawahlunto terdapat beberapa fenomena yang menghambat tercapainya tujuan pembelajaran antara lain adalah guru masih jarang mengembangkan modul sendiri dan bahkan tidak pernah, hal ini terjadi karena banyaknya bahan ajar yang siap pakai sehingga guru tidak wajib mengembangkan bahan ajar yang dapat digunakan. Siswa dominan mendengarkan dan mencatat yang sekaligus menjadi salah satu faktor pembelajaran tidak aktif melibatkan siswa dalam proses pembelajaran. Modul yang sekarang belum sesuai dengan tujuan pembelajaran kurikulum 2013. Kesukaran siswa untuk menggunaka modul karena tidak menarik. Pembelajaran yang berpusat pada guru mengakibatkan perbedaan individual dimana siswa yang cepat memahami harus menunggu siswa yang lambat dalam memahami pembelajaran.

Salah satu tugas guru dalam melaksanakan kurikulum 2013 adalah merubah pandangan pembelajaran yang berpusat pada guru menjadi pembelajaran yang berpusat pada siswa yang memungkinkan siswa dapat terlihat lebih aktif dalam pembelajaran dan saling bekerja sama dalam menemukan pengetahuannya. Salah satu model pembelajaran Dasar Listrik dan Elektronika yang mengacu pada kurikulum 2013 adalah pembelajaran berbasis inkuiri terbimbing. Beberapa keunggulan metode pembelajaran inkuiri adalah siswa menjadi lebih aktif, terlatih berpikir kritis belajar juga menjadi lebih bermakna karena pemahaman dibangun oleh siswa itu sendiri [4]. 
Metode pembelajaran berbasis inkuiri merupakan pembelajaran yang memberi kesempatan kepada siswa untuk terlibat secara aktif dalam proses pembelajaran melalui percobaan atau eksperimen sehingga melatih siswa berkreativitas dan berpikir kritis untuk menemukan sendiri suatu pengetahuan yang pada akhirnya mampu menggunakan pengetahuannya tersebut dalam memecahkan masalah dalam pembelajaran [5]. Penggunaan modul yang disusun berbasis inkuiri terbimbing diharapkan dapat meningkatkan kualitas proses pembelajaran yang pada akhirnya bermuara pada peningkatan kemampuan berpikir kritis [6].

Modul merupakan suatu media pembelajaran yang berisi kesatuan bahan belajar yang di sajikan dalam bentuk "Self-intruction", yang artinya bahwa modul itu dapat dipelajari oleh siswa secara mandiri dengan bantun yang terbatas dari guru [7]. Fungsi modul pembelajaran sebagai ajuan dalam tingkat kebehasilan belajar karena modul menuntut siswa untuk mengukur tingkat kemampuan melalui pembelajaran secara mandiri yang didalamnya terdiri dari materi yang terperinci dan sesuai dengan kompetensi.Unsur-unsur yang terdapat dalam modul yaitu petunjuk belajar untuk siswa dan guru, tujuan pembelajaran, kompetensi yang akan dicapai, orientasi masalah, kegiatan belajar, lembar kerja, kunci lembar kerja, evaluasi, dan kunci evaluasi [8].

Kerangka modul pembelajaran yang dikembangkan terdiri dari deskripsi judul, petunjuk penggunaan modul untuk siswa, kegiatan pembelajaran, tujuan pembelajaran, orientasi masalah, materi pembelajaran, rangkuman, latihan soal, tes formatif, dan kunci jawaban soal. Tugas latihan soal tediri dari soal pertanyaan yang bertujuan untuk mengukur tingkat pemahaman siswa dalam proses pembelajaran yang diberikan oleh guru.Berdasarkan uraian diatas maka disusun suatu bahan ajar pembelajaran yang berbentuk modul berbasis inkuiri terbimbing yang dapat diakses oleh siswa dimana saja melalui laptop atau handpone melalui link yang telah disebarkan dimana saja.

\section{METODE PENELITIAN}

Penelitian pengembangan ini menggunakan jenis metode Research and Development (R\&D) dengan model Define, Design, Develop and Disseminate (4D). Model merupakan seperangkat prosedur yang sistematis pada suatu konsep yang akan menunjukkan penggambarannya seperti keadaan yang sebenarnya. Jenis metode penelitian pengembangan ini ialah penelitian pengembangan yang digunakan untuk menghasilkan sebuah product tertentu dan menguji kevaliditan dan kepraktikalitasnya. Dalam penelitian pengembangan tahap Disseminate tidak diterapkan karena kondisi saat ini sedang pandemic covid-19 yang peserta didiknya harus melakukan pembelajaran dirumah atau online. Penelitian pengembangan yang dilakukan pada mengembangkan modul berbasis inkuiri terbimbing pada mata pelajaran Dasar Listrik dan Elektronika (DLE), dengan responden guru dan siswa kelas X TITL 1 SMK Negeri 2 Sawahlunto dengan jumlah siswa sebanyak 10 orang dan 2 orang guru mata pelajaran Dasar Listrik dan Elektronika pada semester ganjil tahun ajaran 2020/2021.

\section{Validitas Instrumen Penelitian}

Proses validitas ini untuk menghasilkan angket yang akan digunakan valid. Hal ini untuk memperkuat keabsahan data di lapangan agar penelitian dapat dipertanggung 
jawabkan. Validator yang khusus untuk memvalidasi angket tersebut terdiri dari dua orang pakar. Validator mengisi instrumen berupa angket validasi yang telah disediakan untuk menilai instumen yang akan digunakan dan bersedia untuk memberikan masukan terhadap pernyataan-pernyataan yang terdapat pada instrument penelitian. Untuk menentukan validitas instrument digunakan perhitungan model skala Likert [9].

Tabel 1. Indikator Variabel Skala Likert

\begin{tabular}{llc}
\hline No & Indikator & Skor \\
\hline 1 & Sangat Baik & 5 \\
2 & Baik & 4 \\
3 & Cukup Baik & 3 \\
4 & Tidak Baik & 2 \\
5 & Sangat Tidak Baik & 1 \\
\hline
\end{tabular}

Setelah diperoleh hasil validitas, kemudian dapat diketahui nilai kevalidan dengan kategori, seperti tabel 2.

Tabel 2. Kategori Kevalidan

\section{Validitas Produk}

\begin{tabular}{llc}
\hline No & Tingkat Pencapaian & Kategori \\
\hline 1 & $81-100$ & Valid \\
2 & $61-80$ & Tidak Valid \\
\hline
\end{tabular}

Proses validitas ini dilakukan untuk menghasilkan modul pembelajaran yang valid. Modul yang dihasilkan pada tahap ini akan divalidasi oleh tiga validator yaitu dua orang validator dari dosen jurusan Teknik Elektro FT-UNP dan satu orang guru mata pelajaran DLE Kelas X TITL di SMK Negeri 2 Sawahlunto. Validator mengisi instrument penelitian berupa angket validasi yang memberi masukan dan saran terhadap modul yang telah dikembangkan. Untuk mementukan validitas produk yang dihasilkan digunakan perhitungan skala Likert [10].

Tabel 3. Indikator Skala Likert

\begin{tabular}{llc}
\hline No & Indikator & Skor \\
\hline 1 & Sangat Setuju & 5 \\
2 & Setuju & 4 \\
3 & Netral & 3 \\
4 & Tidak Setuju & 2 \\
5 & Sangat Tidak Setuju & 1 \\
\hline
\end{tabular}

Setelah diperoleh hasil validitas, kemudian dapat diketahui nilai kevalidan dengan kategori, seperti tabel 4.

Tabel 4. Kategori Kevalidan

\begin{tabular}{llc}
\hline No & Tingkat Pencapaian & Kategori \\
\hline 1 & $81-100$ & Sangat Valid \\
2 & $61-80$ & Valid \\
3 & $41-60$ & Cukup Valid \\
4 & $21-40$ & Kurang Valid \\
5 & $0-20$ & Tidak Valid \\
\hline
\end{tabular}




\section{Praktikalitas Produk}

Uji Praktilasi berfungsi untuk mengetahui tingkat kepraktisan modul pembelajaran berbasis inkuiri terbimbing pada mata pelajaran Dasar Listrik dan Elektronika. Uji praktikalitas ini hanya dilakukan pada satu kompetensi dasar yaitu 3.3 Sifat elemen pasif rangkaian listrik arus searah dan rangkaian peralihan. Tingkat kepraktisan modul pembelajaran dilihat dari penggunaannya oleh guru dan siswa ketika melaksanakan pembelajaran dengan menggunakan modul yang telah di revisi berdasarkan penilaian validator. Berdasarkan hasil praktikalitasyang diperoleh, kemudian dapat dikategorikan sesuai dengan tingkat kepraktisan seperti pada tabel 5 [11].

Tabel 5. Kategori Kepraktisan

\begin{tabular}{llc}
\hline No & Pencapaian & Kategori \\
\hline 1 & $81-100$ & Sangat Praktis \\
2 & $61-80$ & Praktis \\
3 & $41-60$ & Cukup Praktis \\
4 & $21-40$ & Kurang Praktis \\
5 & $0-20$ & Tidak Praktis \\
\hline
\end{tabular}

\section{HASIL DAN PEMBAHASAN}

Modul pembelajaran dikembangkan menggunakan model pengembangan 4-D. Dalam tahap pegembangan 4-D ada empat tahapan yaitu tahap I Pendefenisian (define), tahap II Perancangan, (design), Tahap III Pengembangan (develop), dan tahap IV Penyebaran (Dissiminate).Tahap Pendefenisian (define) dilakukan untuk mengetahui bagaimana keadaan yang terjadi di lapangan. Sehingga dilakukan analisis kebutuhan modul Dasar Listrik dan Elektronika yang akan dikembangkan. Diantaranya analisis silabus, analisis materi, dan pengumpulan materi untuk perancangan modul. Hasil dari tahap pendefenisian (define) akan digunakan pada tahap perancangan (design) yang terdiri dari menyusun kerangka modul dan menyusun program terperinci yang meliputi semua komponen modul. Tahap pengembangan (development) adalah tahap yang dimana modul yang dikembangkan harus memenuhi kriteria valid dan praktis. Setelah melakukan pengembangan maka tahap terakhir adalah tahap penyebaran (dissiminate). Modul pembelajaran ini disebarkan dalam bentuk hard copy dan softcopy. Penyebaran modul pembelajaran ini dilakukan pada dua orang guru mata pelajaran Dasar Listrik dan Elektronika dan siswa kelas X TITL SMK Negeri 2 Sawahlunto melalui link https://online.flipbuilder.com/uows/nfgd/

Uji Validitas instrumen penelitian oleh satu validator yaitu dari dosen Teknik Elektro Fakultas Teknik Universitas Negeri Padang. Berdasarkan hasil validator diperoleh skor rata-rata persentase nilai sebesar $92 \%$ dengan kategori valid yang artinya instrument penelitian telah memenuhi syarat dalam penelitian.Uji Validitas modul oleh tiga validator yang terdiri dari satu dosen ahli media dan satu dosen ahli materi yang masing-masing dari Teknik Elektro FT-UNP , lalu satu guru sebagai ahli materi di SMK Negeri 2 Sawahlunto. Berdasarkan hasil validasi, validator memberikan perolehan skor 
dengan rata-rata sebesar $88 \%$ dengan kategori sangat valid yang artinya modul pembelajaran telah memenuhi syarat.

Uji praktikalitas pada satu kompetensi dasar yaitu 3.3 dilakukan dengan memberikan angket kepada guru dan siswa sebagai pengguna modul. Responden dalam uji praktikalitas sebanyak 10 orang siswa kelas X TITL 1 dan 2 orang guru mata pelajaran Dasar Listrik dan Elektronika di SMK Negeri 2 Sawahlunto. Adapun tujuan dari uji praktikalitas adalah untuk respon siswa dan guru terhadap kemudahan penggunaan modul yang telah dikembangkan. Berdasarkan rekapitulasi kepraktisan guru mata pelajaran diperoleh hasil sebesar $86,58 \%$ dengan kategori sangat praktis. Uji praktikalitas pada siswa sebagai pengguna modul diperoleh hasil $85 \%$ dengan kategori sangat praktis.

\section{KESIMPULAN}

Berdasarkan analisis data dan pembahasan pada penelitian yang dilakukan, disimpulkan bahwa penelitian pengembangan yang telah dilakukan ini menghasilkan suatu produk bahan ajar modul berbasis inkuiri terbimbing yang valid dan paraktis pada mata pelajaran Dasar Listrik dan Elektronika (DLE) kelas X TITL di SMK N 2 Sawahlunto. Hal ini dibuktikan dari hasil validasi tiga dosen sebagai validator adalah modul yang dikembangkan dikategorikan valid. Hasil uji praktikalitas modul pembelajaran dari guru dan siswa dikategorikan sangat praktis. Berdasarkan penelitian yang telah dilakukan, ada beberapa saran yang dapat diungkapkan sebagai tindak lanjut penelitian, yaitu: Guru SMK supaya dapat menggunakan modul pembelajaran dalam proses pembelajaran.

\section{REFERENSI}

[1] H. E. Alif Alimin, "Pengembangan Modul Pembelajaran Berbasis Daring Pada Mata Diklat Instalasi Penerangan Listrik Kelas XI Di Sekolah Menegah Kejuruan," J. Multidicsiplinary Res. Dev., 2020.

[2] Y. Zega and F. Eliza, "Pengembangan Modul Pembelajaran Dasar Listrik dan Elektronika Untuk Kelas X TITL SMK Negeri 1 Padang," JTEV (Jurnal Tek. Elektro dan Vokasional), 2020, doi: 10.24036/jtev.v6i2.109033.

[3] D. Mahadiraja and Syamsuarnis, "Pengembangan Modul Pembelajaran Berbasis Daring pada Mata Pelajaran Instalasi Penerangan Listrik Kelas XI Teknik Instalasi Tenaga Listrik T.P 2019/2020 di SMK Negeri 1 Pariaman,” Jtev (Jurnal Tek. Elektro Dan Vokasional), 2020.

[4] Depdiknas, "DEPDIKNAS," in Panduan Pengembangan Bahan Ajar, 2008.

[5] Irdalisa, Paidi, and Djukri, "Implementation of technology-based guided inquiry to improve tpack among prospective biology teachers," Int. J. Instr., 2020, doi: 10.29333/iji.2020.1323a.

[6] R. Ruqoyyah, M. A. Fatkhurrohman, and Y. Arfiani, "Implementasi Model Inkuiri Terbimbing Berbantuan Pop-up book untuk Meningkatkan Kemampuan Berpikir Kreatif Peserta Didik," J. Edukasi Mat. dan Sains, 2020, doi: 10.25273/jems.v8i1.6166.

[7] Trianto, "Mendesain Model Pembelajaran Inovetif-Progresif Konsep, Landasan dan Implementasinya pada KTSP," Jakarta: Kencana., 2012.

[8] Sugiyono, "Metode Penelitian Kuantitatif, Kualitatif dan R \& 
D.Bandung:Alfabeta.," Metod. Penelit. Kuantitatif, Kualitatif dan $R$ D.BandungAlfabeta., 2012, doi: 10.1017/CBO9781107415324.004.

[9] Sukardi, "Evaluasi Pendidikan," Jakarta Bumi Aksara, 2008.

[10] Sukardi, "Bab Iii Metode Penelitian a.," Metod. Penelit. Ilm., 2013.

[11] Riduwan, Skala Pengukuran Variabel-variabel Penelitian. 2007. 
Halaman ini sengaja dikosongkan 